whose visual acuity falls short of the legal requirement. After taking the driving test, which includes reading car numberplate letters at a fixed distance, a driver is obliged to notify the Vehicle Licensing Centre as soon as he becomes aware that his vision has deteriorated below the specified standard. On the evidence presented here, most middle-aged people with impaired distant visual acuity are unaware of their disability, a finding that casts doubt on the adequacy of existing legislation.

The slightly higher overall prevalence of visual impairment at the 1972 survey reflected the aging of the whole population over the five years. The lack of significant difference in the prevalence of impaired visual acuity between the screening and control groups suggests that screening had no measurable impact on distance vision. The explanation for this disappointing result probably lies in the multiphasic nature of the screening programme. A large volume of data was presented to each person's general practitioner, who was expected to assess the clinical importance of abnormal findings and, if necessary, arrange further investigation, treatment, and follow-up. Previously reported analyses have shown that the general practitioners initiated treatment for only a few of the abnormalities discovered at screening. ${ }^{2}$ In future studies of multiphasic screening it would be advisable either to reduce the scale of the examinations, concentrating on perhaps one or two systems, or to provide sufficient additional resources to exploit fully the yield of clinical information.

Finally, nearly half the study population claimed to wear spectacles for distant vision. This is five times the proportion found to have impaired distant vision on testing. Unless most of this lens correction is unnecessary spectacle wearing apparently limits the prevalence of impaired visual acuity in the community. More investigation is needed to establish whether improved quality or frequency of optical prescription would reduce it still further. Hopes that mass screening might fulfil such a role have not been realised.

We are indebted to Professor W W Holland and colleagues in the department of community medicine, St Thomas's Hospital Medical School, for their advice and encouragement ; to Dr H J T Woodall and Dr E Tuckman, without whose help the study could not have taken place; and to the Department of Health and Social Security, who partly supported the south-east London screening study.

\section{References}

${ }^{1}$ Holland, W W, Lancet, 1974, 2, 1494

2 South-east London Screening Group, International fournal of Epidemio$\log y, 1977,6,357$

${ }^{3}$ Trevelyan, H, Preventive Medicine, 1973, 1, 278.

4 World Health Organisation, The Prevention of Blindness, WHO Technical Report Series No 518. Geneva, WHO, 1973.

5 D'Souza, M F, Swan, A V, and Shannon, D J, Lancet, 1976, 1, 1228.

${ }_{6}^{6}$ Guralnick, L, Vital and Health Statistics, 1967, series 3, No 7.

7 Cullinan, T, The Epidemiology of Visual Impairment (Part 2). Canterbury, Health Services Research Unit, University of Kent, 1976.

8 Department of Transport of the Department of the Environment, Leafle LF 676. Crowthorne, Transport and Road Research Laboratory, 1977.

(Accepted 24 fuly 1978)

\title{
Effect of cirrhosis of the liver on the pharmacokinetics of chlormethiazole
}

\author{
P J PENTIKÄINEN， P J NEUVONEN， S TARPILA， E SYVÄLAHTI
}

British Medical fournal, 1978, 2, 861-863

\section{Summary and conclusions}

The pharmacokinetics of chlormethiazole were studied in eight patients with advanced cirrhosis of the liver and in six healthy volunteers after oral and intravenous administration of the drug. In the patients the systemic bioavailability of oral chlormethiazole was increased about tenfold, whereas its elimination was only slightly retarded. The increased bioavailability was clearly due to decreased first-pass metabolism of chlormethiazole in the cirrhotic liver.

The results indicate that chlormethiazole should be used in reduced dosage when given by mouth to patients with cirrhosis of the liver.

University of Helsinki, Helsinki, Finland

P J PENTIKÄINEN, MD, senior lecturer, second department of medicine P J NEUVONEN, MD, senior lecturer, department of clinical pharmacology $S$ TARPILA, MD, senior lecturer, second department of medicine

Medical Department, Astra Läkemedel, Södertälje, Sweden E SYVÄLAHTI, MD, senior lecturer

\section{Introduction}

Chlormethiazole is a derivative of the thiazole part of vitamin $B_{1}$, and owing to its sedative-hypnotic and anticonvulsant properties it is widely used for treating restlessness and agitation -for example, in delirium tremens. Although chlormethiazole is thought to be relatively safe, several deaths have been described in association with its use, mostly after excessive dosage..$^{1-4}$ Impaired liver function has been considered as a possible risk factor for chlormethiazole toxicity. ${ }^{3}$ Chlormethiazole is eliminated mainly by metabolism, only a very small amount being excreted unchanged in the urine. Furthermore, oral chlormethiazole undergoes extensive first-pass metabolism, which may be dose-dependent. ${ }^{5-7}$ In view of these properties of chlormethiazole changes could be expected to occur in its pharmacokinetics in patients with cirrhosis of the liver.

We have evaluated the absorption and elimination of chlormethiazole in patients with advanced cirrhosis of the liver and in a group of healthy volunteers.

\section{Subjects and methods}

Eight men with biopsy-proved alcoholic cirrhosis of the liver participated in the study. Laparoscopy with liver biopsy had been performed two to six months before. All had a history of alcohol abuse but abstained from alcohol for at least one month before the study. They had no other significant diseases. Six healthy male volunteers 
served as controls. Informed written consent was obtained from all subjects before starting the study.

Drugs known to induce or inhibit drug metabolising enzymes were not being used by the patients. Spironolactone was replaced by amiloride at least two weeks before the study. Two of the patients had undergone portacaval shunt operations. Clinical and laboratory details of the patients and controls are given in the table.

Clinical and laboratory details of patients with cirrhosis of liver and of healthy volunteers. Values are means $\pm S E$

\begin{tabular}{|c|c|c|c|c|}
\hline & & $\begin{array}{c}\text { Patients } \\
\text { with } \\
\text { cirrhosis } \\
(n=8)\end{array}$ & $\begin{array}{c}\text { Healthy } \\
\text { volunteers } \\
(n=6)\end{array}$ & $\mathbf{P}$ \\
\hline 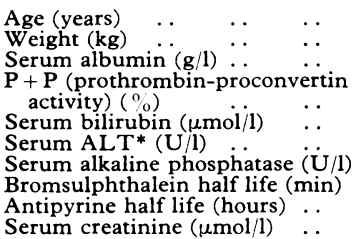 & $\begin{array}{l}\ldots \\
\cdots \\
\cdots \\
\cdots \\
\cdots \\
\cdots \\
\cdots\end{array}$ & $\begin{aligned} 47 & \pm 4 \\
81 & \pm 7 \\
32 \cdot 4 & \pm 2 \cdot 4 \\
& \\
44 & \pm 4 \\
60 \cdot 9 & \pm 17 \cdot 6 \\
25 \cdot 0 & \pm 5 \cdot 5 \\
324 & \pm 18 \\
42 \cdot 0 & \pm 5 \cdot 0 \\
45 \cdot 8 & \pm 9 \cdot 4 \\
74 \cdot 1 & \pm 7 \cdot 1\end{aligned}$ & $\begin{aligned} 47 & \pm 3 \\
74 & \pm 4 \\
43 \cdot 7 & \pm 1 \cdot 8 \\
100 & \pm 3 \\
11 \cdot 7 & \pm 2 \cdot 5 \\
28 \cdot 3 & \pm 7 \cdot 0 \\
170 & \pm 12 \\
5 \cdot 3 & \pm 0 \cdot 8 \\
8 \cdot 0 & \pm 0 \cdot 5 \\
96 \cdot 0 & \pm 6 \cdot 5\end{aligned}$ & $\begin{array}{c}\text { NS } \\
\text { NS } \\
<0.01 \\
<0.001 \\
<0.05 \\
\text { NS } \\
<0.001 \\
<0.001 \\
<0.01 \\
<0.05\end{array}$ \\
\hline
\end{tabular}

*Serum alanine aminotransferase (SGPT).

NS = Not significant

traditional units-Serum bilirubin: $1 \mu \mathrm{mol} / 1 \approx 0.06 \mathrm{mg} / 100 \mathrm{ml}$. Serum creatinine: $1 \mu \mathrm{mol} / 1 \approx 0.01 \mathrm{mg} / 100 \mathrm{ml}$.

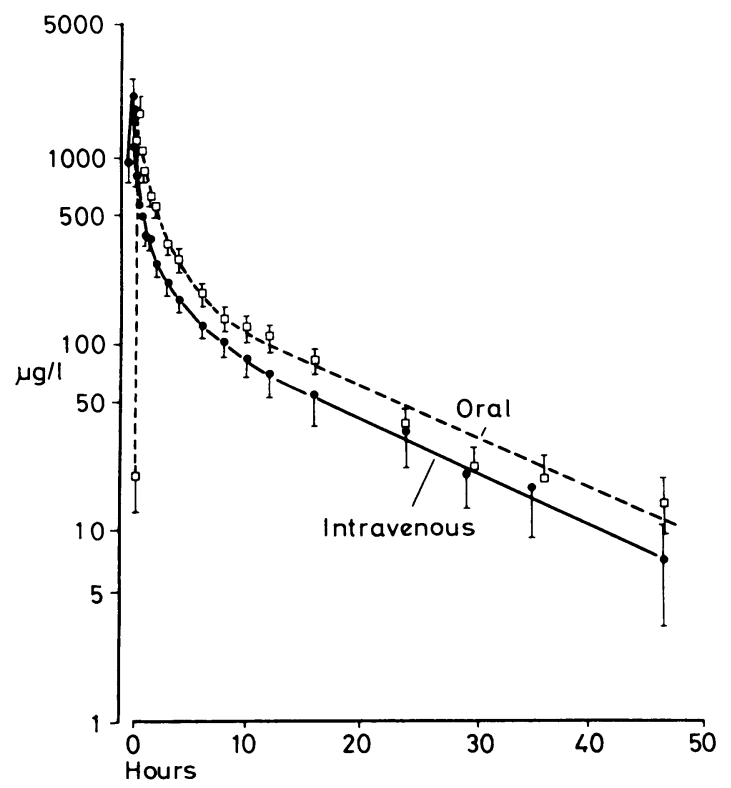

FIG 1-Mean ( \pm SE) plasma concentrations of chlormethiazole in eight patients with cirrhosis of liver after oral and intravenous doses corresponding to $192 \mathrm{mg}$ chlormethiazole (base).

A capsule containing $192 \mathrm{mg}$ chlormethiazole (base) in $384 \mathrm{mg}$ peanut oil was taken by mouth and an equimolar dose given intravenously-that is, $300 \mathrm{mg}$ chlormethiazole edisylate-within 30 minutes on separate occasions at random to each subject. Chlormethiazole was administered at $8 \mathrm{am}$ after an overnight fast. At least four days elapsed between the two studies. Timed venous blood samples were obtained during 48 hours after administration and all urine was collected in fractions for the same period. Routine laboratory tests were performed before the study began. Antipyrine half life was determined between and bromsulphthalein half life after the two chlormethiazole studies.

Chlormethiazole analyses were performed by mass fragmentography. ${ }^{6}$ The areas under the plasma concentration time curves (AUC) were calculated by trapezoidal rule. Extrapolation to infinity was performed using an elimination rate constant obtained from the intravenous (IV) curve. Bioavailability was calculated as the ratio of AUCs after oral and intravenous administration of chlormethiazole. Plasma clearance was calculated as dose/AUC

Student's $t$ test was used to compare means for the two groups.

\section{Results}

Plasma concentrations of chlormethiazole after oral and intravenous administration are given in fig 1 for cirrhotic patients and in fig 2 for healthy volunteers. The mean half lives of the elimination phase for chlormethiazole after intravenous administration were similar in the patients $(8 \cdot 7 \pm \mathrm{SE} 1.4 \mathrm{~h})$ and healthy volunteers $(6.6 \pm 1.0 \mathrm{~h})$. Plasma clearance of chlormethiazole, however, was significantly $(P<0.05)$ slower in the patients $(12.8 \pm 1.7 \mathrm{ml} / \mathrm{min} / \mathrm{kg})$ than in the volunteers $(18 \cdot 1 \pm 1 \cdot 2 \mathrm{ml} / \mathrm{min} / \mathrm{kg})$

In the patients plasma concentrations of chlormethiazole were higher after oral administration than after the same dose given

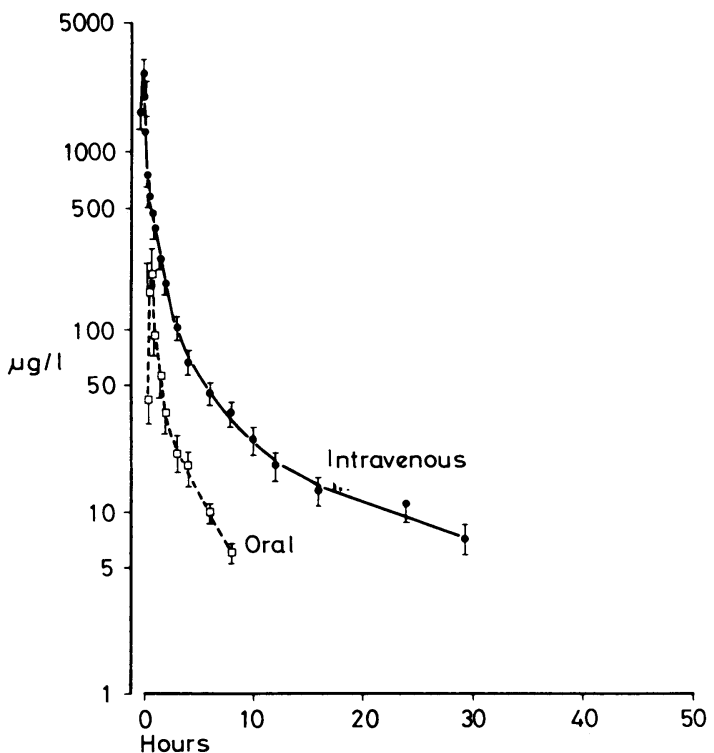

FIG 2-Mean $( \pm S E)$ plasma concentrations of chlormethiazole in six healthy volunteers after oral and intravenous doses corresponding to $192 \mathrm{mg}$ chlormethiazole (base).

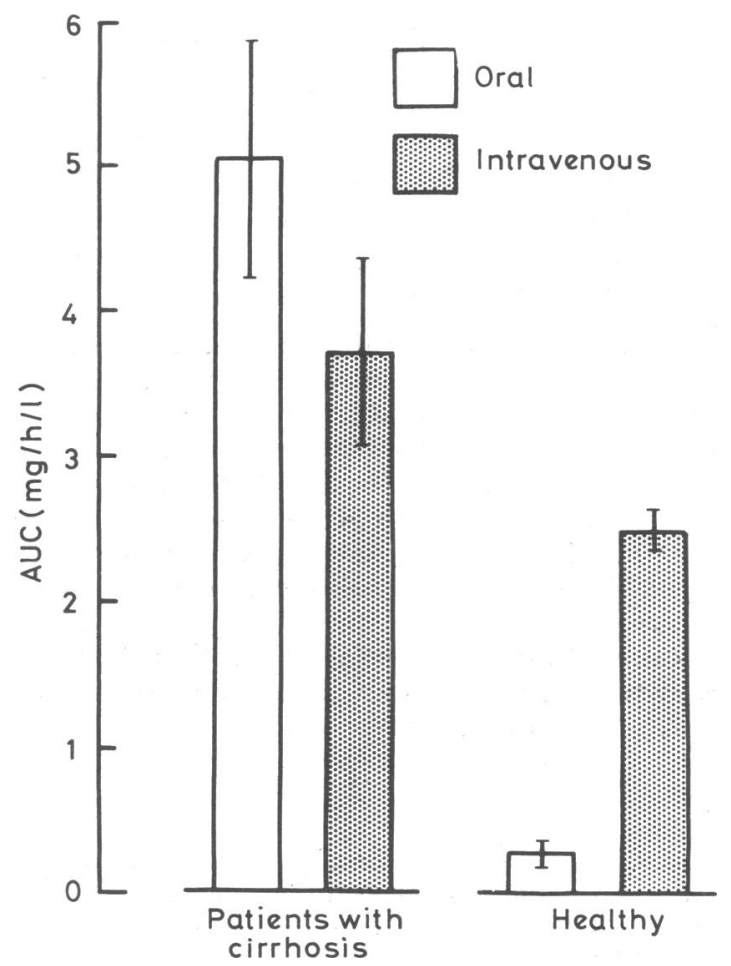

FIG 3-Mean ( \pm SE) areas under plasma chlormethiazole concentration time curve (AUC) in eight patients with cirrhosis of liver and six healthy volunteers after oral and intravenous doses corresponding to $192 \mathrm{mg}$ chlormethiazole (base). 
intravenously. The respective $A U C s$ were $A C_{\text {oral }} 5 \cdot 05 \pm 0 \cdot 81$ $\mathrm{mg} / \mathrm{h} / \mathrm{l}$, and $\mathrm{AUC}_{\mathrm{IV}} 3.73 \pm 0.63 \mathrm{mg} / \mathrm{h} / \mathrm{l}(\mathrm{P}<0.05)$ (fig 3). Thus the $\mathrm{AUC}_{\text {oral }}$ was $136 \pm 11 \%$ of the $\mathrm{AUC}_{\mathrm{IV}}$.

In the healthy volunteers the plasma concentrations of chlormethiazole were much lower after oral administration than after the intravenous dose. The respective AUCs were $A_{U C}$ oral $0.29 \pm 0.07 \mathrm{mg} / \mathrm{h} / \mathrm{l}$, and $A_{U C} C_{I V} 2 \cdot 48 \pm 0.15 \mathrm{mg} / \mathrm{h} / 1(\mathrm{P}<0.001)$ (fig 3$)$. Thus the systemic bioavailability of oral chlormethiazole was $11.8 \pm 2.9 \%$ as compared with the intravenous dose.

Cumulative excretion of unchanged chlormethiazole in urine was less than $0.1 \%$ of the dose over 48 hours. After oral administration it amounted to $9 \pm 8 \mu \mathrm{g}$ in healthy volunteers and $137 \pm 41 \mu \mathrm{g}$ in the patients with cirrhosis $(\mathbf{P}<0.05)$. After intravenous administration there were no significant differences between the groups, the values being $46 \pm 9 \mu \mathrm{g}$ in the volunteers and $60 \pm 11 \mu \mathrm{g}$ in the patients.

The bioavailability of chlormethiazole showed a significant positive correlation with the serum bilirubin concentration $(P<0.05)$, bromsulphthalein half life $(\mathrm{P}<0.001)$, and alkaline phosphatase concentration $(\mathbf{P}<0.001)$ and a significant negative correlation with antipyrine clearance $(P<0.001)$ and $P+P$ (prothrombin-proconvertin activity; $P<0.001$ ) when the values for the patients and controls were pooled (fig 4).

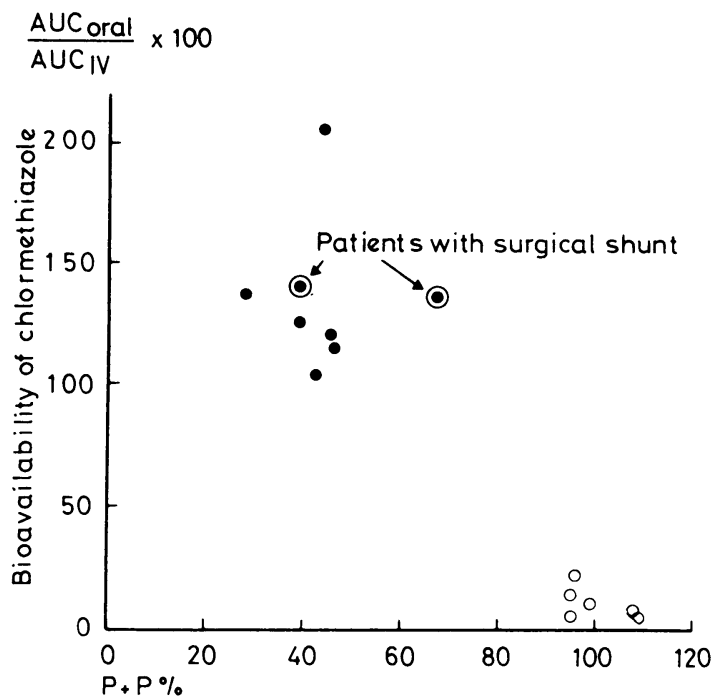

FIG 4-Correlation between bioavailability of chlormethiazole and $\mathrm{P}+\mathrm{P}$ (prothrombin-proconvertin activity) in patients $(\mathbf{O})$ and controls $(O)$

\section{Discussion}

We have shown that the amount of unmetabolised chlormethiazole reaching the systemic blood circulation after an oral dose is about 10 times higher in patients with advanced cirrhosis of the liver than in healthy people. This finding was based on both plasma concentrations and excretion of unchanged chlormethiazole in urine. The finding of low bioavailability of chlormethiazole in healthy subjects, about $12 \%$ of an oral dose of $192 \mathrm{mg}$ (base), accords with other reports. ${ }^{5}$ The low bioavailability was clearly related to the extensive first-pass metabolism, and in this respect chlormethiazole closely resembles propranolol. ${ }^{8}$

In addition to the metabolic capacity of the liver, the hepatic blood flow is of great importance for first-pass metabolism. In advanced cirrhosis of the liver both arterial and portal hepatic blood flow is decreased. Endogenous shunting of portal blood might be an important determinant for the decrease of first-pass metabolism of chlormethiazole after oral administration in patients with cirrhosis. The rather small change in plasma clearance of chlormethiazole after intravenous administration suggests that arterial hepatic blood flow or metabolism of chlormethiazole in the liver is relatively less disturbed. The drug-metabolising capacity of the liver in these patients, however, was decreased as indicated by the prolonged half life of antipyrine.

The kinetic behaviour of antipyrine and chlormethiazole is quite different. Antipyrine has a low hepatic extraction ratio and no first-pass metabolism. Its metabolism is primarily dependent on the metabolic capacity of hepatic tissue and not on hepatic blood flow. In contrast, chlormethiazole has a high hepatic extraction ratio and an extensive first-pass metabolism and its elimination is primarily dependent on hepatic blood flow.

A decrease of hepatic extraction of chlormethiazole during its first pass, as a result of shunting of portal blood or of decreased metabolic capacity, could well lead to a pronounced change in bioavailability, leaving the elimination rate relatively less affected. This phenomenon seems to be common with so-called "flow-limited" drugs with a high hepatic extraction ratio. ${ }^{9}$

The systemic bioavailability of oral chlormethiazole apparently exceeded the theoretical maximum of $100 \%$ in cirrhotic patients when intravenous administration was used as a reference. Nevertheless, as the metabolism of chlormethiazole in the liver is saturable possibly the metabolic capacity of the cirrhotic liver was exceeded after oral administration but not after intravenous infusion. In the latter case the entry of chlormethiazole to the liver is slower and its hepatic concentration remains lower than after oral administration. Thus the saturable metabolism may explain the bioavailability apparently exceeding $100 \%$. Furthermore, very high concentrations of chlormethiazole in the hepatic vascular bed might diffuse into the biliary canaliculi and thence into the hepatic bile, resulting in considerable recirculation after oral administration.

From the results of routine clinical laboratory tests the decrease in $\mathbf{P}+\mathbf{P}$ seemed to be a simple and useful indicator of the bioavailability of oral chlormethiazole.

Prudence has been advised on the basis of clinical experience in the use of chlormethiazole in patients with liver disease, ${ }^{10}$ and the possible role of liver disease in fatal intoxication caused by chlormethiazole has been discussed. ${ }^{3}$ Our results provide further evidence and emphasise the need to use reduced doses of chlormethiazole, especially when given by mouth to patients with advanced liver cirrhosis.

We are indebted to J-E Lindgren for mass-fragmentographic analysis of chlormethiazole. This study was supported by a grant from the Finnish State Medical Research Council.

\section{References}

1 Hossfeld, D, Medizinische Welt, 1969, 33, 1806.

2 Jakobsson, S, and Möller, M, in Abstracts of the Sixth International Meeting of Fore:zsic Sciences, Edinburgh, 1972, p 150 London, Association of the British Pharmaceutical Industry, 1972.

3 Pentikäinen, P J, Valtonen, V V, and Miettinen, T A, International fournal of Clinical Pharmacology and Biopharmacy, 1976, 14, 225.

${ }^{4}$ Horder, J M, British Medical fournal, 1978, 1, 693.

5 Moore, R G, et al, European fournal of Clinical Pharmacology, 1975, 8, 353

${ }^{6}$ Jostell, K G, et al, Acta Pharmacologica et Toxicologica Scandinavica. In press.

${ }^{7}$ Jostell, K G, et al, Clinical Pharmacology and Therapeutics, 1978, 23, 181.

${ }^{8}$ Shand, D G, and Rangno, R E, Pharmacology, 1972, 7, 159.

9 Wilkinson, G R, and Shand, D G, Clinical Pharmacology and Therapeutics, $1975,18,377$

${ }^{10}$ Salum, I, Nordisk Psykiatrisk Tidskrift, 1963, 17, 20.

(Accepted 8 August 1978) 